\title{
Sustainability transition dynamics; Towards overcoming policy resistance
}

Vincent de Gooyert ${ }^{\mathrm{a}, *}$, Etiënne Rouwette ${ }^{\mathrm{a}}$, Hans van Kranenburg ${ }^{\mathrm{a}}$, Edward Freeman ${ }^{\mathrm{b}}$, Harry van Breen $^{\mathrm{c}}$

\begin{abstract}
Sustainability transitions receive major scholarly attention, often explicitly with the intention to develop policy recommendations aimed towards progressing such transitions. Despite these efforts, many implemented transition policies have not been able to meet expectations. This tendency of systems to defeat the policies that have been designed to improve them is known as 'policy resistance'. This paper addresses the question how we can explain the persistence of policy resistance in the context of sustainability transitions, and aims to bring us a step further in the direction of identifying policies that support overcoming policy resistance. System dynamics is an approach that explicitly addresses policy resistance and we investigate how this approach complements existing transition approaches. As an illustration, we apply the approach to the case of the Dutch energy transition, with the participation of 96 experts. We conclude that system dynamics complements the dominant multi-level perspective and the transition management approach by providing a middle ground between emphasizing agency or structure. Moreover, the approach helps overcoming policy resistance by mapping out the structure of the system responsible for policy resistance, thereby enabling the identification of high leverage points that support sustainability transitions.
\end{abstract}

\section{Keywords}

sustainability transition; policy resistance; systems dynamics

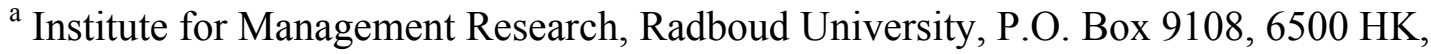
Nijmegen, The Netherlands

${ }^{\mathrm{b}}$ Darden School of Business, University of Virginia, P.O. Box 6550, Charlottesville, VA 22906, USA

${ }^{c}$ Alliander N.V., P.O. Box 50, 6920 AB, Duiven, The Netherlands

* Corresponding author. Tel.: +3124361 17 67; fax: +3124361 1933

E-mail addresses: v.de.gooyert@fm.ru.nl (V.de Gooyert), e.rouwette@fm.ru.nl (E. Rouwette), h.vankranenburg@fm.ru.nl (H. van Kranenburg), freemane@darden.virginia.edu (E. Freeman), harry.van.breen@alliander.com (H. van Breen)
} 


\section{Introduction}

A considerable number of studies have been published on sustainability transitions (Markard et al., 2012). These studies argue that the challenges today's societies face are unprecedented, and that fundamental transformation processes, or transitions, are necessary in order to meet them (Van den Bergh et al., 2011). Examples of such challenges are water and food scarcity, environmental pollution, and climate change (Markard et al., 2012). Sustainability transition studies aim to understand how transitions evolve over time, and often generate explicit policy recommendations to support progressing transitions. The multi-level perspective and transition management are two dominant approaches that are being used to study sustainability transitions (Lachman, 2013).

The multi-level perspective understands sustainability transitions as a coevolution of niches, regimes, and landscapes (Lachman, 2013). Niches are conceptualized as small spaces where innovations in technologies and markets occur (Geels, 2007), while regimes are the broader context in which niches find themselves, consisting of (groups of) actors, their rules and norms, as well as material and technological elements (Geels, 2004). Landscapes represent the even broader trends and global events that provide the context in which regimes are embedded (Lachman, 2013). Transition management is a governance concept specifically developed for the management of sustainability transitions (Loorbach, 2010). Transition management is characterized by a focus on long term thinking, with appreciation for multiple domains, actors, and levels (Rotmans et al., 2001, p.22). It has a focus on learning, on system innovation alongside system improvement, and on keeping a large number of options open.

Policies that have been developed with the use of the multi-level perspective and transition management are meeting considerable policy resistance in practice: "Given recent drawbacks in actual policy contexts (Kern and Smith, 2008; Kern and Howlett, 2009), the role of 
transition management [...] remains to be seen" (Markard et al., 2012). In the Netherlands for example, transition thinking has been the foundation for energy policies for nearly a decade, but results have not been able to meet expectations (Kern and Smith, 2008). Policy resistance is the phenomenon that systems tend to defeat the policies that have been designed to improve them (Sterman, 1994), that "some problems persist in spite of continuous efforts to solve them" (Meadows, 1982, p. 103). The observation that policies brought forward by the multi-level perspective and transition management encounter policy resistance motivates our research questions: how can the persistence of policy resistance in the context of sustainability transitions be explained, and how may policies that overcome policy resistance be identified? Answering these questions allows us to enhance the transition literature, by putting it in a better position to understand and overcome policy resistance.

Policy resistance results from feedback loops pushing systems back towards their initial condition. An approach that explicitly addresses policy resistance and the underlying feedback loops is system dynamics (Sterman, 2000). System dynamics claims to be an approach that supports understanding and overcoming policy resistance, therefore we look in this direction for the answers to our research questions. While applications of system dynamics on transitions are numerous (Fiddaman, 2002; Ford, 1997; Forrester, 1971b; Meadows et al., 1972; Moxnes, 1990; Naill, 1992; Sterman, 1982), surprisingly, a strong connection with the sustainability transition literature has yet to be established. All approaches have their blind spots (Coenen \& Díaz López, 2010), so rather than proposing to use system dynamics instead of the multi-level perspective or transition management, the current study aims to identify how system dynamics complements the multi-level perspective and transition management. As a result, we set out to expand the 'toolbox' of sustainability 
transition scholars and policy makers with the system dynamics approach, putting us in a better position to cope with policy resistance.

Evidence is coming from a case study we conduct in the context of the Dutch energy transition because this is a typical example where policies developed with the multi-level perspective and transition management have been meeting policy resistance (Kern and Smith, 2008). Our case study consists of eight workshops, in which a total of 96 experts from the industry applied system dynamics to explain policy resistance in the Dutch energy system. Using the case study as an illustration, we find that system dynamics complements the dominant approaches by providing a middle ground between emphasizing agency or structure. Moreover, we will show that the approach helps overcoming policy resistance by mapping out the structure of the system responsible for policy resistance, thereby enabling policy makers to identify high leverage points that support sustainability transitions.

In our study stakeholders are directly involved in mapping the system. This facilitated approach to system dynamics modeling is known as group model building (Richardson and Andersen, 1995). Group model building not only helps to elicit and integrate stakeholders' knowledge on the system of interest, but also has been shown to create commitment to proposed policies (e.g. Rouwette et al., 2011). System dynamics, facilitated or not, can be used to develop stock and flow diagrams and simulation models, or it can be used to develop a qualitative model. Because developing a simulation model falls outside the scope of this study, the end result of our modeling efforts consists of a qualitative causal loop diagram.

The remainder of this paper starts with a background on the phenomenon of policy resistance. Subsequently, we present the case study where we apply the system dynamics approach on the Dutch energy transition. This illustration includes a section discussing the background of 
the Dutch energy transition, a section on the methods that have been applied, a section discussing the model that resulted from the case study, and a section providing an analysis of this case, including policy recommendations that aim to overcome policy resistance. After this illustration, we return to the more general level of sustainability transition approaches by comparing system dynamics to the multi-level perspective and the transition management approach, followed by concluding remarks.

\section{Policy resistance}

\subsection{Defining policy resistance}

Policy resistance is the failure of policies to achieve the desired outcome. It is "the tendency for interventions to be delayed, diluted, or defeated by the response of the system to the intervention itself" (Meadows, 1982, in Sterman, 1994, p. 303). Moreover, “many times our best efforts to solve a problem actually make it worse" (Sterman, 2000, p. 3). Already in the 1970s, scholars were discussing the "unexpected, ineffective, or detrimental results often generated by government programs" (Forrester, 1971a, p. 109). Policy resistance occurs when "policy actions trigger feedback from the environment that undermines the policy and at times even exacerbates the original problem" (Ghaffarzadegan et al., 2011, p. 24). Society consists of all kinds of actors, each with their own goals. "Suppose a government intervenes in such a system with a strong policy that actually moves the state of the system toward the government's goal. That will open up greater discrepancies for other actors with different goals, which will cause them to redouble their efforts" (Meadows, 1982, p. 104).

\subsection{Policy resistance in the sustainability transition literature}

The sustainability transition literature is full of references to policy resistance, although not by that name. In its overview of different transition approaches, Lachman 
stresses that transitions, although necessary, may be very hard to bring about due to the fact that "society is often "locked-in" by [...] unsustainable systems of consumption and production" (Unruh, 2000, 2002, in Lachman, 2013, p. 269). Yet another term, in the same overview, is that of "persistent problems": those problems that are "inherent in system structures" (Lachman, 2013, p. 270). In their description of what they call the sustainability transitions field, Markard et al. (2012) explain that sustainability challenges are "aggravated by the strong path-dependencies and lock-ins we observe in the existing sectors" (Ahman and Nilsson, 2008; IEA, 2011; Safarzynska and Van den Bergh, 210; Unruh, 2000, in Markard et al., 2012, p. 955). Van den Bergh mentions the "fundamental barriers" (Van den Bergh, 2011, p. 2) that often plague sustainability transitions, yet another indication of the persistence of policy resistance in this field.

\subsection{Focusing on policy resistance with system dynamics}

Although policy resistance is widely acknowledged in the sustainability transition literature, studies often touch the subject tangentially when setting their stage and studies focusing primarily on this phenomenon are rare. Perhaps related is the observation that policies based on those approaches suffer from policy resistance themselves (Kern and Smith, 2008), which can be seen as a suggestion that dominant transition approaches are not adequately suited to deal with policy resistance. To be able to both understand policy resistance and identify remediating policies, we turn to an approach that explicitly claims to be suitable to this end: the system dynamics approach (Sterman, 2000). According to the founder of this field, Jay W. Forrester (1971a, p. 109), "society becomes frustrated as repeated attacks on deficiencies in social systems lead only to worse symptoms", and "the field of system dynamics now can explain how such contrary results happen". Moreover, 
applying the system dynamics approach "will lead to a better understanding of social systems and thereby to more effective policies for guiding the future" (Forrester, 1971a, p. 109).

A core idea in system dynamics is that numerical data in itself are insufficient to foster an understanding that is rich enough to capture the structure responsible for policy resistance, and that mental models should also be accessed. Group model building is a tradition focusing on how to access and represent the mental models of groups of experts (Vennix, 1996). Earlier examples of studies capturing mental models of experts to explain policy resistance are Perlow (2002), Repenning and Sterman (2002), and Van Oorschot and Akkermans (2013). However, these studies collected data on the level of single organizations. Sustainability transitions are so complex, that for the current study, eight workshops with experts are held. To our best knowledge, group model building has yet not been applied to understand policy resistance on such a large scale. System dynamics and group model building are discussed in more depth below, but first we provide some more background on the Dutch energy transition.

\section{The case of the Dutch energy transition}

In 2012 more than $85 \%$ of the Dutch energy consumption was covered by oil and natural gas (primary energy consumption in 2012, BP, 2013). The Port of Rotterdam provides the Netherlands with easy access to oil. What distinguishes the Netherlands the most from other European countries however, is its reliance on natural gas. This stems from the fact that the Netherlands has a large reserve of natural gas in the province of Groningen (with a proven reserve of 1.0 trillion cubic meters at the end of 2012, BP, 2013). In cooperation with private parties, the Dutch government has been extracting natural gas for several decades (Verbong and Geels, 2007). 
Since the energy crisis in the early 1970s, the Dutch government has been developing energy policies that include increasing the energy system's sustainability (Van Rooijen and Van Wees, 2006). Over time, a range of policies has been implemented but the effectiveness of these policies remains limited: a large gap between goal and current situation remains. Policies aimed at increasing the share of renewable electricity for example ranged consecutively from voluntary agreements, to the promotion of demand, and finally to the promotion of supply (Van Rooijen and Van Wees, 2006). By frequently changing policies, the government has not been able to reduce market uncertainties and to instill confidence in market parties (Van Rooijen and Van Wees, 2006). While sustainability became more and more prominent in policy rhetoric, the changes that did occur in the Dutch energy system were mainly driven by broader trends such as Europeanization and liberalization, with environmental aspects remaining in the periphery (Verbong and Geels, 2007).

Since the early 2000s the Dutch policies are explicitly aimed at bringing about an energy transition using the transition management approach, including the appointment in 2001 of a 'transition manager' who is responsible for managing the 'energy transition project', and the appointment in 2005 of a 'task force energy transition' with 17 members from both private and public parties (Kern and Smith, 2008). The taskforce and its transition management however, had no substantial impact on the energy policy (Kern and Smith, 2008). While the transition efforts were explicitly aimed at incorporating various organizations in identifying policies, the partnerships soon became dominated by elites from the government and the fossil industry (Hendriks, 2008). The 'transition storyline' referred to 'niche innovations' that lead to 'system changes', but as incumbents captured the governance of the transition, the potential for change diminished (Smith and Kern, 2009). Established players played too great a role, standing in the way of effective transition management (Kemp et al., 2007). 
In 2013 new energy policies were issued. Following a request from the Dutch government, the Dutch Social and Economic Council facilitated a process in which a wide variety of parties arrived at an agreement on how to meet the national objectives. One of these objectives is the goal of 16\% renewable energy production by 2023 (SER, 2013), compared to a current share of $4.7 \%$ (PBL, 2012). A total of 40 organizations signed the socalled 'Energy Agreement' that was the result of this process, including “central, regional and local government, employers and unions, nature conservation and environmental organizations, and other civil-society organizations and financial institutions" (SER, 2013, p.1). According to large Dutch daily newspapers, this agreement is again meeting considerable policy resistance (NRC, 2016; Volkskrant, 2015).

\section{Method}

To provide an illustration of how policy resistance may be explained and policies may be identified with the system dynamics approach, we apply the approach on the Dutch energy transition (Sterman, 2000). System dynamics supports a better understanding of complex systems by identifying the causal relations between both physical and behavioral components that together provide an explanation for the behavior of the system as a whole (Forrester, 1961). The starting point is that closed circles of causal relations, called feedback loops, are the main determinants of system behavior and as such provide the strongest leverage points for interventions (Richardson, 1991), as such the feedback loops can both help explain why certain behavior was observed in the past, as well as forecasting what the effects of interventions will be in the future. These feedback loops come in two forms. Balancing feedback loops give a system the tendency to come back to the position that it started from. Policy resistance then, can be understood as the failure to take balancing feedback loops affecting a certain goal variable into account (Ghaffarzadegan et al., 2011, p. 24). Identifying 
these balancing feedback loops helps to understand why systems have the tendency to delay, dilute, or defeat interventions. Reinforcing feedback loops on the other hand, explain why some systems have the tendency to amplify any intervention inflicted on them. Even a small change in one of the variables within such a loop could have drastic results.

An example of a balancing feedback loop that is well known in the energy literature is the rebound effect (Herring and Sorrell, 2008). The rebound effect entails that investments in energy conservation often come with side effects that offset the original saving (Antal and Van den Bergh, 2014, p. 587). An example is a family that buys a car with higher fuel efficiency, potentially saving energy because the car requires less gallons of fuel to travel the same distance as before. Because they are saving on fuel the family may be tempted to increase the distance they travel, thereby pushing the system back to the point it came from.

An example of a reinforcing feedback loop that is well known in the energy literature is the learning effect (Bergek and Onufrey, 2013). An investment in a certain technology may lead to improvements in that technology because of the additional experience that is gained through the investments. The investment thereby increases the attractiveness to invest even more in to that same technology, compared with competing technologies that did not benefit from the former investment. This effect has also been described under the labels of path dependency (Bergek and Onufrey, 2013) and the 'success to the successful' system archetype (Senge, 1990).

A sustainability transition can be understood as a transformation in a complex system consisting of several feedback loops. With this understanding, successfully managing a sustainability transition becomes a matter of identifying high leverage points in those feedback loops that can support the progression of the transition, thereby overcoming policy resistance. System dynamics supports the identification of high leverage points by creating "maps of the feedback structure" (Sterman, 1994, p. 192), or causal loop diagrams. Below we 
present an illustration hereof, by applying the system dynamics approach on the Dutch energy transition, a case of policy resistance.

To involve a wide variety of stakeholders with various viewpoints, we organized several workshops according to the format as put forward in group model building literature (Vennix, 1999). Group model building is specifically suited for workshops where a variety of stakeholders is involved to collaboratively structure a problem (Rouwette et al., 2011). A model building process consists of stakeholders participating in workshops in which they construct a representation of that part of reality that is relevant for a certain issue (Franco and Montibeller, 2010), in our case the Dutch energy transition. The model is built step by step and to ensure that the model accurately captures the viewpoints of the participants, after each step the question is asked whether all participants agree with the extension of the model. In our study, the model takes the form of a causal loop diagram: a diagram showing the relevant variables and the causal relations that link them (Vennix, 1996).

To ensure that there was enough room for interaction we aimed to keep the number of participants in each workshop low. It is the interaction that facilitates the exchange of arguments and the building of the model. On the other hand, we wanted to incorporate a wide diversity of viewpoints, which is served by including more participants. Therefore, we chose to organize eight separate workshops that are exactly the same in their design, except for the stakeholders that participated. The workshops resulted in eight separate models of the Dutch energy transition, see Appendix A. Identifying the similarities between these eight models enabled us to aggregate them in a single model, which we present in the results section below.

We invited stakeholders in collaboration with the Dutch Distribution System Operator Alliander that co-organized the workshops. Various employees of Alliander helped by pointing out relevant stakeholders in their networks. The starting point for these invitations 
was the desire to include the widest variety of viewpoints possible. We invited a total of 329 experts from the energy sector. The number of participants per workshop varied from eight to fifteen, with a total of 96 participants over all eight workshops. Participants represented different stakeholder groups: 27 represented infrastructure (transmission, distribution), 25 services (consultants, bankers, lawyers), 18 industry (manufacturing, energy supply), 17 government (national, local), and 9 other (research, NGOs). Preparing the workshops and inviting the stakeholders started in June of 2013. The workshops took about five hours each and took place in September and October of 2013. Each workshop was led by two facilitators that were familiar with the group model building method.

\section{Case results}

In eight workshops, stakeholders with a wide variety of viewpoints engaged in a dialogue on the Dutch energy transition. In each workshop the following question was guiding: "How can we explain the current development of the Dutch energy transition?" There were several lines of thought that came back in all the separate workshops. We describe these shared lines of thought below, representing those mechanisms on which there was consensus between the groups. We support the description with a causal loop diagram that we build up step by step. This diagram is a summary of the eight causal loop diagrams that were constructed in the workshops: elements that recurred throughout the different workshops were included in the summarizing diagram and elements that were mentioned in just some but not all of the workshops were left out. Excerpts from the eight workshops that supported the aggregation into one model are provided in Table 1 through 5 below, with numbers before the excerpts representing the various participants of the workshops. 


\subsection{Increasing sustainability and coping with intermittent renewable energy production}

The energy transition is a transition towards a more sustainable energy system. An energy system can be seen to consist of two parts: the part of energy demand, and the part of energy supply. On both sides the sustainability of an energy system may be improved. The demand side consists of energy consumption by for example households, industry, and transportation. Sustainability on the demand side may be improved by energy conservation. Energy conservation may consist of decreasing the consumption of energy, or increasing the efficiency of energy consumption (decreasing the units of energy consumed per unit of output). The supply side of energy consists of the various ways of energy production, for example by combustion engines, central electricity plants and decentralized electricity production. Sustainability on the supply side may be improved by increasing the share of renewable energy production, for example by installing wind mills, solar panels, and so on. In terms of our model we represent this as follows: investments in renewable energy production and energy conservation lead to a higher sustainability of the energy system, see Figure 1.

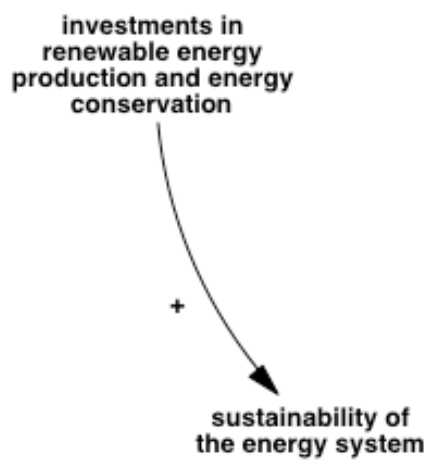

\footnotetext{
${ }^{1}$ The causal loop diagram below may be read as follows. If variables A and B are connected by an arrow with a plus sign, this means: if variable A increases variable B increases as well, and if variable A decreases variable B decreases as well. If two variables are connected by an arrow with a minus sign this means: if variable A increases variable B decreases, and if variable A decreases variable B increases.
} 


\section{Figure 1: Renewable energy production and energy conservation increase sustainability}

When substantial investments are made in renewable energy production and energy conservation this leads to side effects. An important side effect that was mentioned in the workshops is the intermittency that comes as a consequence of a higher share of renewable energy production. Windmills and solar panels for example only produce energy when the circumstances are right (enough wind but not too much, enough solar radiation). This intermittency has as a consequence that the demand and supply of energy are less aligned compared to fossil energy. To ensure the reliability of the energy system despite this intermittency, considerable investments are necessary. Investments in energy infrastructures may help to counteract the regional discrepancy between demand and supply, by transporting energy over larger distances. By transporting energy, local shortages and surpluses can be balanced. Besides, investments in energy storage may help to counteract the temporal discrepancy between demand and supply, by forming a buffer. Investments in the advanced use of information technology could support balancing demand and supply, often referred to as 'smart grids'.

Investments in renewable energy production lead to intermittency and to counter this, additional investments are necessary. These additional investments add to the total costs of renewable energy production. These higher costs have as a consequence that the attractiveness of new investments decreases. The costly side effects of renewable energy production in this way create a balancing feedback loop, as is shown in Figure 2. 


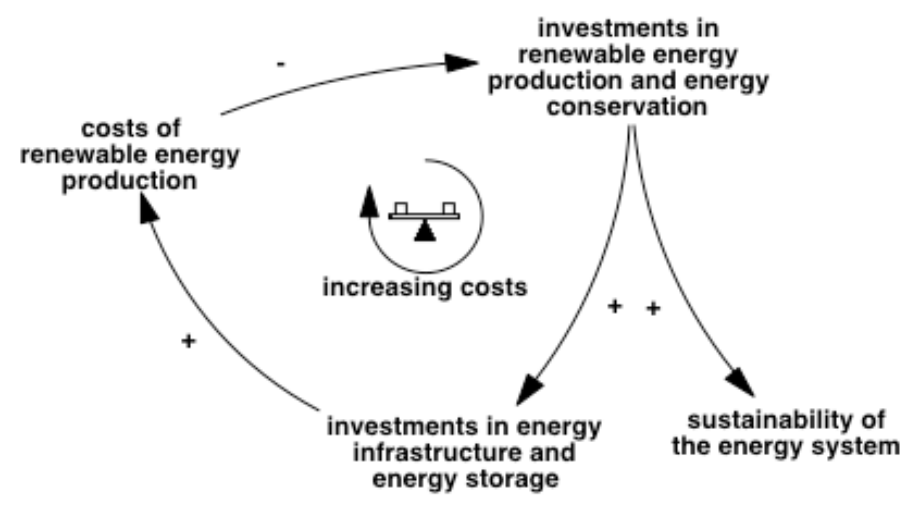

\section{Figure 2: Investments in renewable energy production have costly side effects}

Excerpts from the eight workshops that supported the identification of feedback loop 1

'Increasing costs' are presented in Table 1 below.

\begin{tabular}{|c|c|}
\hline $\begin{array}{l}\text { Work } \\
\text { shop }\end{array}$ & Feedback loop 1 'Increasing costs' \\
\hline 1 & $\begin{array}{l}\text { 8: "If you want to use renewable sources like wind and the sun that can not be controlled, you will have to store } \\
\text { energy. 2: "Unless you could use information technology to manage the demand side." 2: "It is very costly [...] } \\
\text { the more flexible you want to be, the more costly it is." }\end{array}$ \\
\hline 2 & 2: "If you look at wind energy for example, that is inherently intermittent." \\
\hline 3 & $\begin{array}{l}\text { 5: "Energy storage. I think that eh, especially for solar and wind, if you're betting on those two, you have to take } \\
\text { the intermittency into account." }\end{array}$ \\
\hline 4 & 3: "It is difficult to switch to renewable energy, because it requires huge additional investments." \\
\hline 5 & $\begin{array}{l}\text { 12: "Supply and demand, those two should be balanced }[\ldots] \text { Energy storage is an essential part of the solution." } \\
\text { 2: "The location of supply and demand is often far apart [...] you will have to invest in transportation." }\end{array}$ \\
\hline 6 & 6: "Renewable energy is often intermittent, fossil energy is much more flexible." \\
\hline 7 & $\begin{array}{l}\text { 9: "The production of renewable energy is intermittent, so you have to store energy, or transport it to distant } \\
\text { locations." 6: "That's how you get to smart grids." 10: "Demand side management." }\end{array}$ \\
\hline 8 & $\begin{array}{l}\text { 15: "The aspect of time is very important for renewable energy, and therefore the availability of energy storage." } \\
6: \text { "In the end it is about the balance between supply and demand }[. . .] \text { You could change the tariffs, there are } \\
\text { several ways to influence demand." }\end{array}$ \\
\hline
\end{tabular}

Table 1: Excerpts from eight workshops on feedback loop 1 'Increasing costs'

\subsection{Dynamics in the public opinion and in energy markets}

The lower the sustainability of the energy system, the higher the chance that this leads to negative publicity. Examples are oil disasters or the environmental impact of shale gas that receives attention by environmental action groups and newspapers. This publicity leads to more visibility of the environmental impact of the energy system. This increased visibility 
fuels civil unrest on environmental impact. This unrest consequently can incite investments in renewable energy production and energy conservation. This causal chain via visibility of the impact and civil unrest has a balancing effect, see Figure 3.

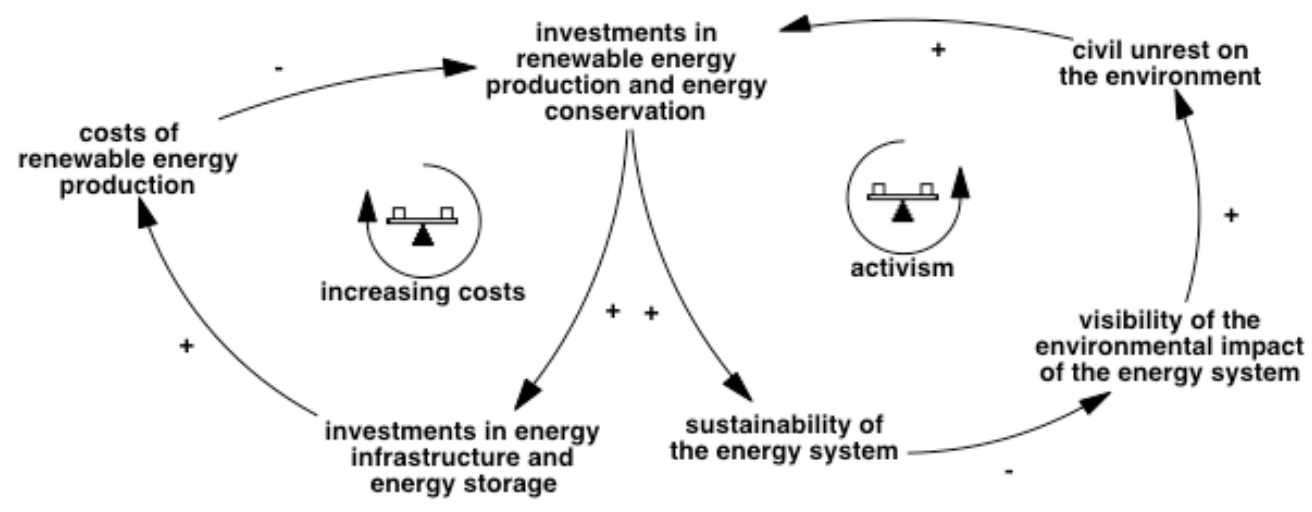

Figure 3: Unrest over environmental impact incites investments in sustainability

Excerpts from the eight workshops that supported the identification of feedback loop 2

'Activism' are presented in Table 2 below.

\begin{tabular}{|c|c|}
\hline $\begin{array}{l}\text { Work } \\
\text { shop }\end{array}$ & Feedback loop 2 'Activism' \\
\hline 1 & $\begin{array}{l}\text { 12: "I'm thinking about awareness of energy consumption"; 7: "[Investments in sustainability such as solar } \\
\text { panels], that's an issue of awareness." }\end{array}$ \\
\hline 2 & $\begin{array}{l}\text { 6: "If the big energy companies fail to address the greening of the energy system, people start to get convinced } \\
\text { they have to do it themselves." } 2: \text { "[CO2 emissions] would result in civil unrest, if it is perceived as detrimental } \\
\text { to the future of our planet". 5: "[Especially] if there are catastrophes..." } 6: \text { :If it's very direct, very visible..." }\end{array}$ \\
\hline 3 & $\begin{array}{l}\text { 9: "Decentralized energy [...] stimulates the production of renewable energy." } 10 \text { : "Those initiatives emerge from } \\
\text { climate awareness, aversion of large energy corporations, the desire to be independent, that sort of factors." }\end{array}$ \\
\hline 4 & 5: "Societal legitimacy could be added [...] of wind, carbon capture and storage." \\
\hline 5 & $\begin{array}{l}\text { 3: "In my perception, the transition is about the individual, about autonomy and ehm, local.." } 4 \text { : I'm convinced } \\
\text { that there is an enormous drive in eh, a group to change the energy system." } 13: \text { :I think we at least agree that if } \\
\text { awareness increases, the consumption of fossil energy decreases." } 10: \text { "There is certainly a relation there: if } \\
\text { [energy consumption] is harmful, and that's what we've seen, then [the energy transition] becomes more urgent." }\end{array}$ \\
\hline 6 & $\begin{array}{l}\text { 8: "Look, if we would all give a high priority to [the energy transition], if we would all feel the urgency, then it } \\
\text { would simply come about." } 12 \text { : "If the CO2 emissions increase }[\ldots] \text { the sense of urgency will also increase." } 2 \text { : } \\
\text { "Exactly, it's a circle." }\end{array}$ \\
\hline 7 & $\begin{array}{l}\text { 3: "Climate can be linked to climate awareness, and then you can close the loop by linking awareness with eh, } \\
\text { behavior." 7: "[If climate awareness increases] the environmentally conscious behavior of consumers will } \\
\text { increase." 9: "I think [If climate awareness increases], the political commitment will increase, the political will to } \\
\text { change." 3: "And decentralized energy production will increase." 6: "As well as energy conservation." }\end{array}$ \\
\hline 8 & 1: "Sense of urgency $[\ldots]$ to what extent do people realize that the energy transition is really necessary." 15 : \\
\hline
\end{tabular}




\section{Table 2: Excerpts from eight workshops on feedback loop 2 'Activism'}

The cost structure of renewable energy production differs from fossil energy production. What characterizes for example windmills and solar panels are the high initial costs (purchase and installment), and the low variable costs. Maintenance costs do return but the wind and solar radiation that are converted into energy are free. Fossil energy production like coal and gas plants have much higher variable costs, as the plants have to buy fuel for as long as they produce energy. When capacity for renewable energy production is installed, this has a decreasing effect on the market price of energy. When windmills and solar panels are installed, they increase the availability of energy on the market, causing a decrease of the market price of energy. During the workshops several participants brought up the cases of Denmark and Germany, where the energy market price has occasionally been negative, due to the fact that on those moments supply was considerable larger than demand, and the possibilities of energy storage are still limited.

A high energy market price is an incentive for energy consumers to decrease their dependency on energy from the market. By investing in their own renewable energy production and in energy conservation, consumers reduce their need to buy energy from the market. The lower market price counteracts this incentive. Therefore, the feedback loop along energy market price has a balancing effect, see Figure 4. 


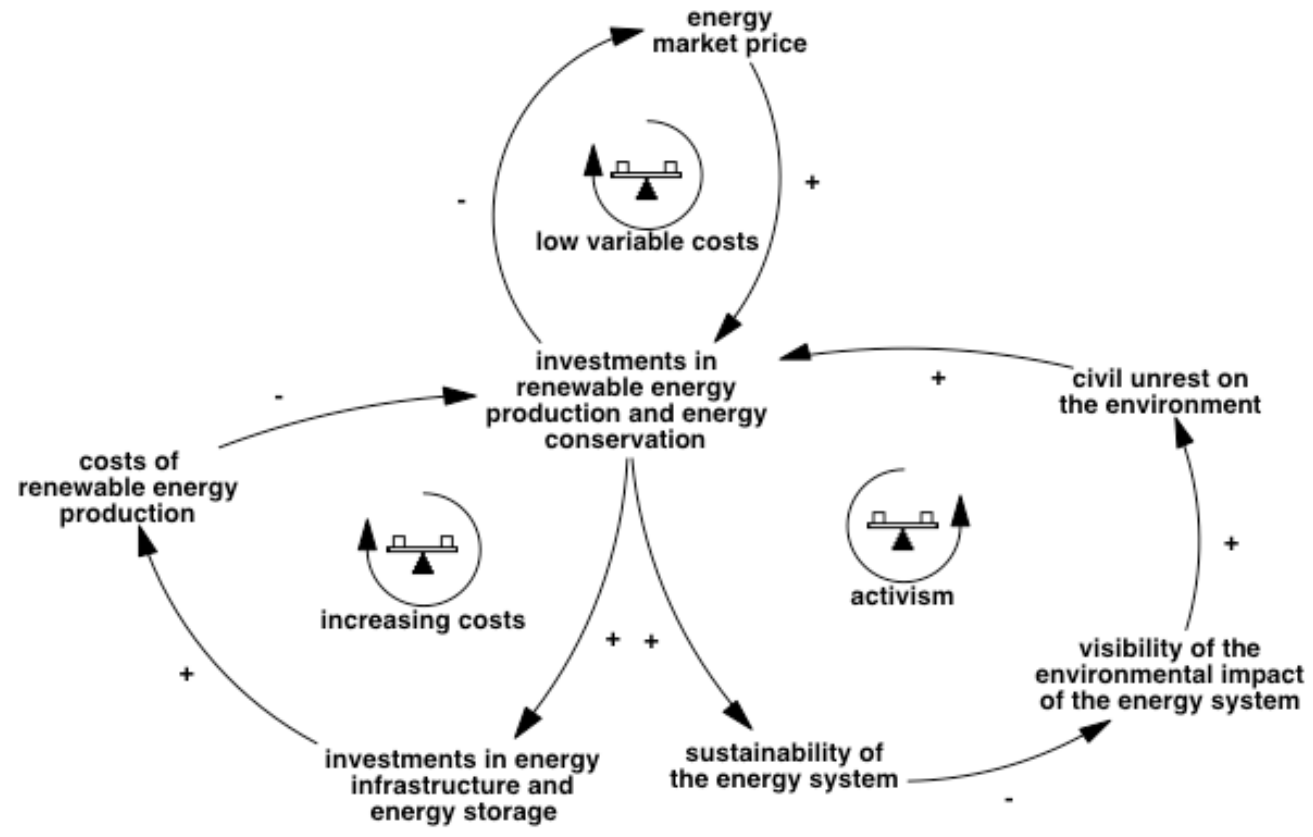

Figure 4: A lower energy market price decreases the incentive for investments in

\section{sustainability}

Excerpts from the eight workshops that supported the identification of feedback loop 3 'Low

variable costs' are presented in Table 3 below.

\footnotetext{
Work Feedback loop 3 'Low variable costs'

shop

$1 \quad$ 7: "If the costs of energy go up, companies will start to innovate, they will look for new solutions." 6: "The price of electricity has decreased, because of the surplus in production capacity."

2 6: "The higher the production of renewable energy, the lower the price of electricity. That's very strange, counterintuitive, but that is what is happening right now [...]." 2: "That's true, because the market price is based on the marginal cost of production and for various forms of renewable energy the costs are not in the operation, but in the initial costs."

3 5: "You have to do the initial investments, both for fossil energy and for renewable energy. But for renewable energy, that's it, while for fossil energy you continue to pay for coal and gas."

4 10: "It's a law that also holds in other domains, for example: the moment we invent faster means of transportation, people will not spend less time travelling, but they will travel further [...] The rebound effect $[\ldots]$ If you save on energy consumption on one place, it pops up in another place."

5 5: "The driver for the head of a household to contribute to the energy transition is primarily price based, I'm certain of that."

6 8: "If there is a surplus in supply, the price will go down."

$7 \quad 1$ : "[Take the example of supermarkets that lower their prices], it has been shown that as a consequence, consumers spend more." 10: "Yes, that's the rebound effect." 3: "If the price of fossil energy goes up, the payback period of investments in the energy transition decreases. That's one of the strongest drivers to become more sustainable. It's a risk for the energy transition that shale gas causes energy prices to drop." 7: "If the costs go up, you will try to find different solutions."
} 


\section{Table 3: Excerpts from eight workshops on feedback loop 3 'Low variable costs'}

\subsection{The politics of the energy transition: vested interests and governments}

The strong position of the fossil industry was a recurring theme throughout the workshops. The exploitation of the Dutch gas reservoir and the historically grown position of fossil multinationals have as a consequence high vested interests, and these interests are seen as conflicting with a transition towards more sustainability. Two expressions of these interests are the following. First, the energy system is designed for fossil energy, which allows for large economies of scale for fossil energy and makes adaptations costly. This translates into a negative relation between the power of vested interests and the market price of energy. While the power of a single supplier would lead to a monopoly and higher prices, the reasoning in the workshops was that the high power of the fossil energy industry as a whole leads to economies of scale resulting in lower costs of producing fossil energy and thereby a lower energy price. Second, the Dutch national policy is geared towards fossil energy. The government depends on the gas exploitation for a substantial part of its income and the fossil industry has a large voice in setting policy. This translates into a negative relation between the power of vested interests and the extent to which the policy is geared towards energy transition.

Through investments in renewable energy production and energy conservation, the power of vested interests will decrease. When an increasing share of the system is adapted to renewable energy the economies of scale will appear in the renewable sector as well. Because of renewable alternatives the government will decrease its income based on fossil fuels and the new parties will gain a larger voice in stipulating new policy. Both mechanisms result in 
reinforcing effects. We label these processes creative destruction in the market for energy and overturning policies, see Figure 5.

There are two relations that relate the variables described earlier with the feedback loops we just described. The additional costs of investing in energy infrastructure and energy storage to meet the intermittency of renewable energy, mentioned earlier, strengthen the power of vested interests. In the workshops participants brought forward that the fossil industry uses the negative side effects of renewable energy to feed anxiety for negative effects of the energy transition, protecting their interest in this way. The civil unrest mentioned earlier that may follow from publicity on environmental problems increases the pressure on the government to adapt policies to facilitate the energy transition. Both relations are included in Figure 5. With these additions we finished the model that represents the core of the eight workshops.

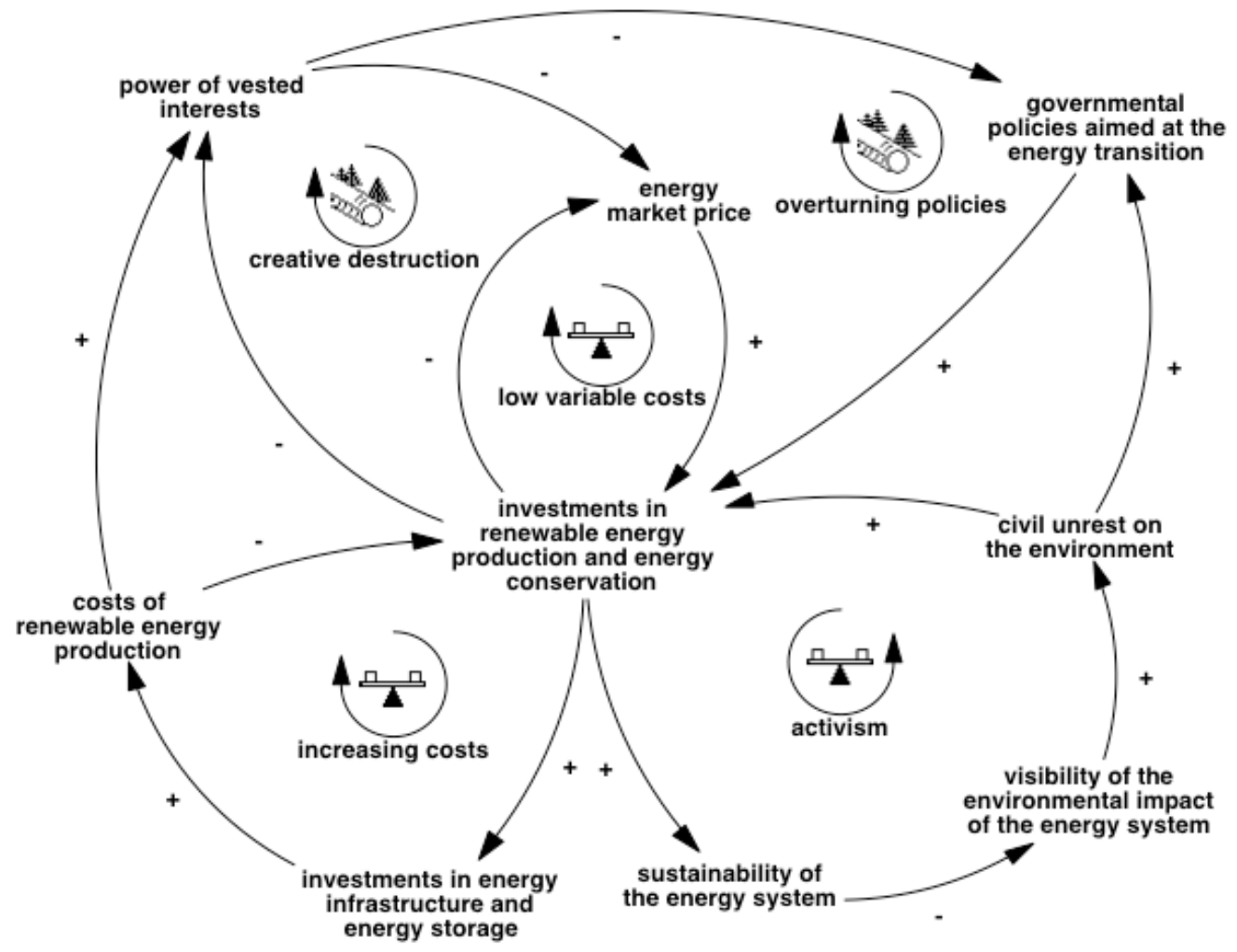

Figure 5: Relation technological, ecological, social, economic, and political factors 
Excerpts from the eight workshops that supported the identification of feedback loop 4

'Creative destruction' are presented in Table 4 below.

\begin{tabular}{|c|c|}
\hline $\begin{array}{l}\text { Work } \\
\text { shop }\end{array}$ & Feedback loop 4 'Creative destruction' \\
\hline 1 & $\begin{array}{l}\text { 3: "I'm thinking of eh, amortization, or eh, the lifecycle of infrastructure." 7: "Technology lock-in." 3: "Yes, } \\
\text { that's it. So if you can think of something to speed up the amortization, you support the energy transition." }\end{array}$ \\
\hline 2 & $\begin{array}{l}\text { 6: "I seriously believe that there is a crisis in the boardrooms of [the large energy corporations]." 2: "The } \\
\text { business model does not fit the current and future market conditions." 6: "If there is a lot of renewable energy } \\
\text { production, the natural gas power station is no longer profitable." }\end{array}$ \\
\hline 3 & $\begin{array}{l}\text { 11: "Power stations are not built for just ten years." T: "[Lock-in] caused by the accumulation of investments in } \\
\text { the infrastructure of the energy system." } 4 \text { : "The higher the accumulated investments in the fossil energy } \\
\text { infrastructure, the lower the market price of fossil energy will be, compared to renewable energy. That's part of } \\
\text { the lock-in effect." }\end{array}$ \\
\hline 4 & $\begin{array}{l}\text { 10: "The inertia of existing infrastructures." 3: "The whole system, both demand and supply, are designed for } \\
\text { fossil energy." 10: "It's the power of vested interest." 3: "Yes, the lock-in effect." }\end{array}$ \\
\hline 5 & $\begin{array}{l}\text { 7: "Power, influence, financial interests of the actors eh, from the old paradigm. [...] If [a large energy } \\
\text { corporation] wants to dig for shale gas, that will happen in The Netherlands." } 7: \text { :And this might tip over to the } \\
\text { power of the cleantech industry." 2: "[The power of vested interests] influences the production of renewable } \\
\text { energy not directly but, I believe, through price mechanisms." }\end{array}$ \\
\hline 6 & $\begin{array}{l}\text { 3: "Interests, or eh, resistance to change." 12: "The power of vested interests." 3: "Some actors try to maintain the } \\
\text { current situation." 9: "You could say that the vested interests have power, but the new actors also have power, it's } \\
\text { about the ratio of those two." }\end{array}$ \\
\hline 7 & 8: "If you have more innovation in fossil exploration for example, this brings down the price of fossil energy." \\
\hline 8 & 1: "The energy transition [...] is the total replacement of fossil energy by renewable energy." \\
\hline
\end{tabular}

Table 4: Excerpts from eight workshops on feedback loop 4 'Creative destruction'

Excerpts from the eight workshops that supported the identification of feedback loop 5

'Overturning policies' are presented in Table 5 below.

\footnotetext{
Work Feedback loop 5 'Overturning policies'

shop

1 9: "Encouraging policies, that support sustainability [...] those would contribute to the energy transition." 2: "For example the possibility of net metering, those sort of things." 10: "The taxes on energy, that's an important driver."

26 : "It's often the government that reacts to such a growing societal concern [...] if everybody screams for renewable energy the government will take measures". 3: "We know that [natural gas] is the government's cash cow. Subsidies shouldn't compete too much with the government's current cash flows."

3 11: [The lock-in effect of the power of the vested interests] also includes the government and its financial dependencies." ?: "I believe it's very important for societal legitimacy that a lot of energy is produced decentralized [and] I believe that eventually, if there is more legitimacy, that consistent governmental policies will follow".

4 11: "The government's business model. They depend on eh, the income from natural gas and so on, to maintain a healthy financial situation."

5 4: "If we hadn't any interest in natural gas, we would have had more wind energy." 3: "[Investments in renewable energy are influenced by] all kinds of regulations, such as whether net metering is allowed or not." 6: "If awareness [on the necessity of the energy transition] increases, this increases the legitimacy of policy measures." 3: "I think that eh, the power of vested interests are involved in determining where subsidies are spent."

69 9: "The legal framework: tax policies is one of them, but also regulations eh, and subsidies. I believe the legal framework is crucial in explaining the current progress of the energy transition."
} 

subsidy on renewable energy] simply reduces the payback period of solar panels." 1: "From climate awareness, you could reason, via policital commitment, stimulating policies will emerge." barrier for the energy transition."

\section{Table 5: Excerpts from eight workshops on feedback loop 5 'Overturning policies'}

\section{Case analysis and recommendations}

In the case study we made an attempt to explain policy resistance in the Dutch energy transition. In this section, we use findings from the model presented above to give policy recommendations, to illustrate how the system dynamics approach facilitates overcoming

policy resistance. We conceptualized the energy system as consisting of several subsystems. The model as provided in Figure 5 shows how these subsystems interrelate, it shows how technological, ecological, social, economic, and political factors influence each other either directly or indirectly. The identified balancing feedback loops explain the policy resistance that plagues the Dutch energy transition. Some of these feedback effects, like the rebound effect (Herring and Sorrell, 2008) and the learning effect (Bergek and Onufrey, 2013) which we both described earlier in this paper, have become well known within the literature and we will restrain from repeating them here. Below, we provide three directions of policy recommendations based on the findings from the model.

\subsection{Use combinations of policies to mitigate side effects}

Interventions that aim to improve only one of the subsystems of the energy transition will result in policy resistance in terms of unintended side effects in other subsystems, because of the strong relations between the subsystems as shown in Figure 5. One example of such an effect is the following. Imagine that the Dutch government would invest heavily in both energy conservation and renewable energy production. It follows from the model in 
Figure 5 that these investments would have a positive effect on the sustainability of the energy system, thereby lowering environmental concerns of citizens through the 'activism' loop. This will lead to lower investments by households in energy conservation and renewable energy production. In this way, there is a 'crowding out effect' of communitybased investments by government spending (Menges, 2003). In general, policy resistance may be remedied by designing combinations of interventions that affect the different subsystems, so that unintended effects in related subsystems are counteracted. For example, one might envision government programs that do not crowd out private investments, for instance by combining conventional investments in energy conservation and renewable energy production with providing funds to support grassroots activities (Seyfang and Haxeltine, 2012), thereby diminishing the balancing effect of the 'activism' loop.

The need for an integrated approach is a direct consequence of considering the energy transition as a problem of the energy system as a whole (Hjorth and Bagheri, 2006), and as such resonates with earlier calls for integrated approaches in the transition literature (Van den Bergh et al., 2011). An integrated approach acknowledges that the interests of stakeholders are interconnected (Freeman, 1984). Rather than searching for optimal trade-offs, policies remediating policy resistance should be focused on enhancing the overlapping interests. A system of carbon taxation for example helps to align the interest of the fossil industry with the interest of environmental stakeholders, thereby increasing the effectiveness of the reinforcing 'creative destruction' loop.

\subsection{Intervene to prevent the market from being spoiled by cheap energy}

Besides the crowding out effect discussed above, investments in renewable energy production have a more direct unintended consequence. A counterintuitive insight that followed from the model is that subsidizing renewable energy production as a consequence 
lowers the incentive to invest in additional renewable energy production through the 'low variable costs' loop, thereby constituting policy resistance. Renewable energy production is characterized by high up-front costs and low variable costs. Once the renewable energy production capacity is installed, the energy market is supplied with energy that has low costs during times of high solar and wind energy, as observed in Spain (Sáenz de Miera et al., 2008) and Germany (Sensfuß et al., 2008). Fossil energy production is faced with substantially higher marginal costs because generators continue to run on fuel. Several participants in the workshops mentioned the low, and on occasion even negative, spot prices on the German and Danish electricity market as an example of this effect.

High electricity prices may be one of the reasons for energy consumers to decide to build their own renewable electricity production. In doing so, they lower their sensitivity to energy market price volatility. The decrease in energy market price due to the increased renewable energy production lowers the motivation for energy consumers to build their own capacity. To overcome this form of policy resistance, we recommend combining support for renewable energy production with other policies, like carbon dioxide emissions pricing (Hirth and Ueckert, 2013), thereby diminishing the balancing effect of the 'low variable costs' loop.

\subsection{Intervene to provide incumbents with a realistic exit strategy}

Given a certain demand for energy, new energy production capacity is only necessary in the pace that old energy production capacity is decommissioned. Fossil power plants typically have a lifetime of several decades, and in the Netherlands several new fossil power plants have been built in the 90s (Graus and Worrell, 2009). This makes the Dutch energy transition substantially different from the transitions in countries that either do not currently have a large number of fossil power plants such as Denmark (Lund and Mathiesen, 2009), or countries that explicitly chose to close down nuclear power plants because of safety reasons 
such as Germany (Smith Stegen and Seel, 2013). If the Dutch energy transition objectives are to be met this asks not just for building renewable energy production capacity in addition to fossil capacity, but this asks for the replacement of fossil production capacity by renewable energy production capacity.

The model in Figure 5 shows that the two reinforcing feedback loops that speed up the energy transition both include the 'creative destruction' (Schumpeter, 1942) of the fossil industry. Because of their strong potential for change, leverage points are expected in these reinforcing feedback loops. Policies aimed at overcoming policy resistance by supporting this ‘creative destruction' may consist of shifting investments from fossil industries and of reducing the threats that accompany such a shift by compensating financial losses for fossil companies (Arbuthnott and Dolter, 2013). Providing an exit strategy for incumbents is a strategy that could be applicable to various transitions, in a variety of locations, but especially applies to the Dutch energy transition, because of the important role that the gas and oil industry play in the Dutch energy system. If policies ensure a reasonable exit for incumbents, this may be an important way of overcoming policy resistance in de Dutch energy transition, by increasing the effectiveness of the reinforcing 'creative destruction' loop.

\section{Discussion}

Policy resistance is a persistent problem in sustainability transitions and current sustainability transition approaches have been insufficient to overcome policy resistance. Therefore, the current study asked the research questions: how can the persistence of policy resistance in the context of sustainability transitions be explained, and how may policies that overcome policy resistance be identified? System dynamics is an approach that claims to support understanding policy resistance in the past as well as overcoming it in the future. This paper provided a case study in which the system dynamics approach was applied to the case of the 
Dutch energy transition. As such, the case study provided an illustration of how system dynamics supports explaining the persistence of policy resistance, as well as how policies to overcome policy resistance in the future may be identified. In this section, we discuss how system dynamics complements existing sustainability transition approaches.

\subsection{Performing a balancing act between structure and agency}

Like all studies in the social sciences, sustainability transition studies face the dilemma of either overemphasizing structure or overemphasizing agency (Giddens, 1984). The pitfall of overemphasizing structure is that the explanation why things are as they are becomes so strong, that there seems to be no more room left for change. The dominant perspectives in sustainability transition literature, transition management and the multi-level perspective, have been criticized for exactly that (Smith et al., 2005, in Geels, 2011). By emphasizing how hard it is to overcome the lock-in effects in systems, they lead to general, defeatist conclusions: sustainability transitions take generations to come about (Lachman, 2013), and only incremental changes are possible (Markard et al., 2012). While a focus on structure helps understanding why transitions are hard to come about, and supports understanding the phenomenon of policy resistance, it provides little help for identifying ways to overcoming policy resistance.

System dynamics has always had a paradoxical position in this respect: "attempts to relate system dynamics to strict notions of voluntarism or determinism quickly indicate that the field does not fit with either pole [...], placing system dynamics with respect to traditional social theory is highly problematic" (Lane, 2001a, p. 97, see also Lane, 2001b). On the surface, a causal loop diagram seems to be strongly fatalistic in its nature. It provides an extensive description of all causal relations that matter to a system, suggesting that once a course of action has started, nothing will be able to change the path of events that has been 
set in motion. On second thought however, it becomes clear how agency has been at the heart of the approach from the start. In system dynamics, the only reason to draw causal loop diagrams is to find those policy levers that best allow decision makers to steer the system in the desired direction.

Although the structure of the system, the relations that determine how variables coevolve, may be unalterable, agents have discretionary space to adjust the parameters that determine the strength of the different relations throughout this structure. Sustainability transitions are deeply embedded in the structures of social reality. Individual (groups of) decision makers either face this in the form of policy resistance when trying to implement policies that failed to take this embeddedness into account, or they use it in their favor by designing policies based on a thorough understanding of that structure. System dynamics provides an approach that aids the development of such an understanding, thereby complementing the transition management approach and the multi-level perspective. By providing a middle ground between overemphasizing structure or agency, system dynamics is in position to support both understanding and overcoming policy resistance.

\subsection{Mapping the structure of the system}

Sustainability transitions are prone to policy resistance. The aim of this paper was to enrich the toolbox of sustainability transition scholars and policy makers with system dynamics, in order to put them in a better position to cope with policy resistance. We found the system dynamics approach as a field that explicitly addresses policy resistance (Forrester, 1971a). How then does this approach differ from the dominant sustainability transition approaches, and how does it complement them? As illustrated in this paper with the case of the Dutch energy transition, system dynamics supports improving understanding a system by drawing up the feedback loops that together determine the results that policies shall have, in 
our case study in the form of a causal loop diagram (Vennix, 1996). By identifying the feedback loops, causal loop diagrams uncover the source of policy resistance (Ghaffarzadegan et al., 2011) and support the identification of high leverage points within those feedback loops (Forrester, 1971a).

Drawing up a causal loop diagram fits in the 'problem structuring' phase of the transition management cycle, a governance process as prescribed in the transition management approach (Loorbach, 2010). During the problem structuring phase, various stakeholders collaborate to unravel the complexity of the system at hand (Loorbach, 2010, p. 173 and further). System dynamics may be used in this step to improve the extent to which the transition management approach is able to deal with policy resistance.

The multi-level perspective focuses on the interfaces of technology niches and existing regimes (Kemp, 1994). Drawing up a causal loop diagram may also assist such an effort because such a diagram could include both levels. The diagram of the Dutch energy transition in this paper for example included different levels by showing how investments in renewable energy and energy conservation are driven by and impact broader communities, politics and markets. It may as such be seen as an analysis of where technology and existing regimes meet.

Although the multi-level perspective has become an enormously rich tradition with a wide collection of case studies on transitions, it provides little guidance to how a system should be systematically charted (Markard and Truffer, 2008, in Geels, 2011, p. 31). System dynamics may complement the multi-level perspective by providing a procedure for systematically determining which technological niches and which existing regimes are relevant to a certain system, what their relevance consists of, in what way this results in policy resistance and how this may be overcome. 


\section{Concluding remarks}

\subsection{Comprehensibility over comprehensiveness}

The data used in the current paper consists of over 40 hours of discussions between experts from the energy industry. This provided us with a very rich source of data, and a very large challenge to simplify the data in order to be able to present a compelling and insightful model. As described earlier in the paper we simplified our model by aggregating eight separate models into one summarizing model. In this aggregation, we prioritized comprehensibility over comprehensiveness. Instead of trying to include all details that were brought to table by all energy experts, we only included those phenomena that were described in all of the eight separate workshops. As a consequence, the model presented in this paper does not include everything that was discussed during the workshops. Rather, it is representative of those things on which there was considerable consensus between the energy experts. Therefore, the model should be seen as an image of some of the most important phenomena that help explain policy resistance in the Dutch energy system. As a downside, the model may not be seen as a complete image of the energy system and leverage points for overcoming policy resistance may exist outside the phenomena on which experts agree.

\subsection{How many stakeholders are enough?}

Like all methods that rely on the input of participating experts, our study only answers the research question in so far as this answer was 'in the room'. We used no other data than the discussion between the various experts in our study. Reliability of the results could be improved by including an even larger variety of experts, or by including other types of data or modeling such as stock and flow models and forecasts by simulation models with sensitivity analyses as often used in system dynamics to triangulate our findings (Bleijenbergh et al., 2010). Due to the nature of our selection process only energy experts 
participated in the workshops. In future research it would be recommended to consider involving other parties, like consumer related groups, in order to provide an even wider variety of viewpoints on the energy system.

Although we succeeded in taking a range of aspects into account, we had to choose a boundary for our analysis. We chose to limit our analysis to the Dutch energy system, ignoring the potential of changing European (Kanellakis et al., 2013) or global energy policies. Future studies may broaden this boundary.

\subsection{Blind spot for politics}

System dynamics supports remediating policy resistance by providing a better understanding of dynamic systems. By identifying the balancing feedback loops that give a system the tendency to return to its previous state, even after interventions, policy makers are informed about the structure underlying the system causing its behavior. This implies that system dynamics can only be helpful in remediating policy resistance in so far as this resistance was caused by a limited perception of the system at hand, by a "misperception of feedback" (Sterman, 1994, p. 303). A perfect perception of the system however, is not a sufficient condition to overcome policy resistance. Although not within the scope of this paper, other sources of policy resistance may (co-) exist. The power dimension of implementing policies can be seen as one of such sources. Policy makers may have a flawless understanding of the system they want to intervene in, but if individual stakes prevent them from coming to an agreement on implementing high leverage policies, such an understanding will not lead to improvements. In this way, system dynamics seems to have a blind spot that is similar to those of the dominant transition approaches, the multi-level perspective and transition management. These too have been criticized for their lack of attention to the political dimension of the policy process (Geels, 2011). 


\section{Acknowledgements}

Funding for this project was provided by Next Generation Infrastructures and Alliander. We thank all participants of the workshops for their contributions. We thank our colleagues at Radboud University, Birgit Fokkinga, Hubert Korzilius, Inge Bleijenbergh, and Marleen McCardle, for helping with facilitating the workshops. 


\section{References}

Åhman, M., Nilsson, L.J., 2008. Path dependency and the future of advanced vehicles and biofuels. Util. Policy 16, 80-89.

Antal, M., van den Bergh, J.C.J.M., 2014. Re-spending rebound: A macro-level assessment for OECD countries and emerging economies. Energy Policy 68, 585-590.

Arbuthnott, K.D., Dolter, B., 2013. Escalation of commitment to fossil fuels. Ecol. Econ. 89, 7-13.

Bergek, A., Onufrey, K., 2013. Is one path enough? Multiple paths and path interaction as an extension of path dependency theory. Ind. Corp. Chang. 23, 1261-1297.

Bleijenbergh, I., Korzilius, H., Verschuren, P., 2010. Methodological criteria for the internal validity and utility of practice oriented research. Qual. Quant. 45, 145-156.

BP, 2013. Statistical review of world energy.

Coenen, L., Díaz López, F.J., 2010. Comparing systems approaches to innovation and technological change for sustainable and competitive economies: an explorative study into conceptual commonalities, differences and complementarities. J. Clean. Prod. 18, 1149-1160.

Fiddaman, T.S., 2002. Exploring policy options with a behavioral climate-economy model. Syst. Dyn. Rev. 18, 243-267.

Ford, A., 1997. System Dynamics and the Electric Power Industry. Syst. Dyn. Rev. 13, 5785.

Forrester, J.W., 1961. Industrial Dynamics. M.I.T. Press, Cambridge (MA).

Forrester, J.W., 1971a. Counterintuitive behavior of social systems. Theory Decis. 2, 109-140.

Forrester, J.W., 1971b. World dynamics. Wright-Allen Press.

Franco, L.A., Montibeller, G., 2010. Facilitated modelling in operational research. Eur. J. Oper. Res. 205, 489-500.

Freeman, R.E., 1984. Strategic Management: A Stakeholder Approach. Boston: Pitman.

Geels, F.W., 2004. From sectoral systems of innovation to socio-technical systems. Res. Policy 33, 897-920.

Geels, F.W., 2007. Analysing the breakthrough of rock "n" roll (1930-1970) Multiregime interaction and reconfiguration in the multi-level perspective. Technol. Forecast. Soc. Change 74, 1411-1431. 
Ghaffarzadegan, N., Lyneis, J., Richardson, G.P., 2011. How small system dynamics models can help the public policy process. Syst. Dyn. Rev. 27, 22-44.

Giddens, A., 1986. The Constitution of Society: Outline of the Theory of Structuration.

Graus, W., Worrell, E., 2009. Trend in efficiency and capacity of fossil power generation in the EU. Energy Policy 37, 2147-2160.

Hendriks, C.M., 2008. On inclusion and network governance: The democratic disconnect of Dutch energy transitions. Public Adm. 86, 1009-1031.

Herring, H., Sorrell, S. (Eds.), 2008. Energy efficiency and sustainable consumption: The rebound effect. Palgrave Macmillan.

Hirth, L., Ueckerdt, F., 2013. Redistribution effects of energy and climate policy: The electricity market. Energy Policy 62, 934-947.

Hjorth, P., Bagheri, A., 2006. Navigating towards sustainable development: A system dynamics approach. Futures 38, 74-92.

IEA, 2011. World Energy Outlook 2011. Paris.

Kanellakis, M., Martinopoulos, G., Zachariadis, T., 2013. European energy policy-A review. Energy Policy 62, 1020-1030.

Kemp, R., 1994. Technology and the transition to environmental sustainability. Futures 26, 1023-1046.

Kemp, R., Rotmans, J., Loorbach, D., 2007. Assessing the Dutch Energy Transition Policy: How Does it Deal with Dilemmas of Managing Transitions? J. Environ. Policy Plan. 9, 315-331.

Kern, F., Howlett, M., 2009. Implementing transition management as policy reforms: a case study of the Dutch energy sector. Policy Sci. 42, 391-408.

Kern, F., Smith, A., 2008. Restructuring energy systems for sustainability? Energy transition policy in the Netherlands. Energy Policy 36, 4093-4103.

Lachman, D.A., 2013. A survey and review of approaches to study transitions. Energy Policy 58, 269-276.

Lane, D.C., 2001a. Rerum cognoscere causas: Part I ? How do the ideas of system dynamics relate to traditional social theories and the voluntarism/determinism debate? Syst. Dyn. Rev. 17, 97-118.

Lane, D.C., 2001b. Rerum cognoscere causas: Part II?Opportunities generated by the agency/structure debate and suggestions for clarifying the social theoretic position of system dynamics. Syst. Dyn. Rev. 17, 293-309. 
Loorbach, D., 2010. Transition Management for Sustainable Development: A

Prescriptive, Complexity-Based Governance Framework. Governance 23, 161-183.

Lund, H., Mathiesen, B.V., 2009. Energy system analysis of 100\% renewable energy systems-The case of Denmark in years 2030 and 2050. Energy 34, 524-531.

Markard, J., Raven, R., Truffer, B., 2012. Sustainability transitions: An emerging field of research and its prospects. Res. Policy 41, 955-967.

Markard, J., Truffer, B., 2008. Technological innovation systems and the multi-level perspective: Towards an integrated framework. Res. Policy 37, 596-615.

Meadows, D., 1982. Whole Earth Models and Systems. Co-Evolution Q. 98 - 108.

Meadows, D.H., MeadowsS, D.L., Randers, J., Behrens, W. W., I., 1972. The limits to growth. A report for the Club of Rome's project on the predicament of mankind. Universe Books.

Menges, R., 2003. Supporting renewable energy on liberalised markets: green electricity between additionality and consumer sovereignty. Energy Policy 31, 583-596.

Moxnes, E., 1990. Interfuel substitution in OECD-European electricity production. Syst. Dyn. Rev. 6, 44-65.

Naill, R.F., 1992. A system dynamics model for national energy policy planning. Syst. Dyn. Rev. 8, 1-19.

NRC, 16 February 2016, Windenergie neemt toe, maar kabinet nog ver af van doelstelling Energieakkoord

PBL, 2012. Climate and energy roadmaps towards 2050 in north-western Europe. The Hague/Bilthoven, the Netherlands.

Richardson, G.P., 1991. Feedback Thought in Social Science and Systems Theory. University of Pennsylvania Press, Philadelphia (PA).

Richardson, G. P., Andersen, D. F., 1995. Teamwork in group model building. Syst. Dyn. Rev., 11, 113-137.

Rotmans, J., Kemp, R., Asselt, M. van, 2001. More evolution than revolution: transition management in public policy. Foresight 3, 15-31.

Rouwette, E.A.J.A., Korzilius, H., Vennix, J.A.M., Jacobs, E., 2011. Modeling as persuasion: the impact of group model building on attitudes and behavior. Syst. Dyn. Rev. 27, 121.

Sáenz de Miera, G., del Río González, P., Vizcaíno, I., 2008. Analysing the impact of renewable electricity support schemes on power prices: The case of wind electricity in Spain. Energy Policy 36, 3345-3359. 
Safarzyńska, K., van den Bergh, J.C.J.M., 2010. Demand-supply coevolution with multiple increasing returns: Policy analysis for unlocking and system transitions. Technol. Forecast. Soc. Change 77, 297-317.

Schumpeter, J.A., 1942. Capitalism, Socialism and Democracy. Harper, New York (NY).

Senge, P.M., 1990. The Fifth Discipline: The Art \& Practice of The Learning Organization. Doubleday/ Currency, New York (NY).

Sensfuß, F., Ragwitz, M., Genoese, M., 2008. The merit-order effect: A detailed analysis of the price effect of renewable electricity generation on spot market prices in Germany. Energy Policy 36, 3086-3094.

SER, 2013. Energy agreement for sustainable growth. The Hague, the Netherlands.

Seyfang, G., Haxeltine, A., 2012. Growing grassroots innovations: exploring the role of community-based initiatives in governing sustainable energy transitions. Environ. Plan. C Gov. Policy 30, 381-400.

Smith, A., Kern, F., 2009. The transitions storyline in Dutch environmental policy. Env. Polit. 18, 78-98.

Smith, A., Stirling, A., Berkhout, F., 2005. The governance of sustainable socio-technical transitions. Res. Policy 34, 1491-1510.

Smith Stegen, K., Seel, M., 2013. The winds of change: How wind firms assess Germany's energy transition. Energy Policy 61, 1481-1489.

Sterman, J., 1982. The energy transition and the economy: a system dynamics approach.

Sterman, J.D., 1994. Learning in and about complex systems. Syst. Dyn. Rev. 10, $291-$ 330.

Sterman, J.D., 2000. Business dynamics: Systems thinking and modeling for a complex world. Irwin McGraw-Hill, Boston (MA).

Unruh, G.C., 2000. Understanding carbon lock-in. Energy Policy 28, 817-830.

Unruh, G.C., 2002. Escaping carbon lock-in. Energy Policy 30, 317-325.

Van den Bergh, J.C.J.M., Truffer, B., Kallis, G., 2011. Environmental innovation and societal transitions: Introduction and overview. Environ. Innov. Soc. Transitions 1,

Van Rooijen, S.N.M., van Wees, M.T., 2006. Green electricity policies in the Netherlands: an analysis of policy decisions. Energy Policy 34, 60-71.

Vennix, J.A.M., 1996. Group model building: facilitating team learning using system dynamics. John Wiley \& Sons, Inc. 
Vennix, J.A.M., 1999. Group model-building: tackling messy problems. Syst. Dyn. Rev. 15, 379-402.

Verbong, G., Geels, F., 2007. The ongoing energy transition: Lessons from a sociotechnical, multi-level analysis of the Dutch electricity system (1960-2004). Energy Policy 35, 1025-1037.

Volkskrant, 22 December 2015, Eerste Kamer tegen wet Kamp: Energieakkoord dreigt te kapseizen 